\title{
Physical and Mechanical Properties of Deep Oceanic Sediments Cored from the Bottom of Challenger Deep, Mariana Trench
}

\author{
Xu Dai, Tao Xu $(\mathbb{D}$, and Jian Chen \\ School of Civil Engineering, Southeast University, Nanjing, Jiangsu 210096, China \\ Correspondence should be addressed to Tao Xu; xu-tao@seu.edu.cn
}

Received 7 April 2021; Accepted 12 May 2021; Published 14 June 2021

Academic Editor: Huie Chen

Copyright ( $2021 \mathrm{Xu}$ Dai et al. This is an open access article distributed under the Creative Commons Attribution License, which permits unrestricted use, distribution, and reproduction in any medium, provided the original work is properly cited.

\begin{abstract}
The deep oceanic sediments were collected from the Challenger Deep in the southwestern part of the Mariana Trench. Considering the salt in the pore water, a modified method for determining the physical and mechanical properties of the deep-sea sediments was proposed, by which the geological engineering indices were measured and corrected. Through the scanning electronic microscope (SEM), the microstructures of the sediments were found to be composed of flocculation, with a large number of diatom debris and empty shells of organism around it. As a consequence, the porosity and compressibility are high; internal friction angle and cohesion are low. Besides high water content, high porosity, high liquid limit, high plasticity, high consolidation coefficient, low compressive modulus, low shear strength, low density, and low specific gravity, the deep-sea mining machine may slip and subside. This research can improve the understanding of the deep-sea sedimentary environment of the Challenger Deep in the southwestern part of the Mariana Trench and provide an essential reference for the parameter calibration as well as the basis for walking-characteristic study and optimization design of the deep-sea mining vehicle.
\end{abstract}

\section{Introduction}

The Mariana Trench subduces the Pacific plate to the lower part of the Philippine plate, leaving behind a series of residual and active island arcs $[1,2]$. "Hadal trench" refers to the abyss with a depth of more than $6000 \mathrm{~m}$, which is the deepest and unknown region on earth. The Challenger Deep is located in the southwest of the Mariana Trench, with a maximum measured depth of $10917 \mathrm{~m}$ [3]. The Mariana Trench area has a unique ecological environment system and contains a large number of mineral resources compared to other seabed areas $[4,5]$, so it has greatly stimulated scholars' enthusiasm for the development utilization of this area [6]. Besides, there are great differences between deep-sea sediments and terrestrial sediments. For example, the deep-sea sediment has high water content, high porosity, low density, low gravity, and high consolidation coefficient [7]. When the deep-sea mining machine works on the seabed [8], to make it run stably on the seafloor and avoid sinking into the seabed sediments, the investigation of the physical and mechanical properties of deep oceanic sediments is important for the selection of driving path and parameters of the deep-sea mining machine.

However, due to the difficulty in obtaining deep oceanic sediments, limited sediment samples in this area were received by various national research institutions, which cannot meet the experimental requirements. The available reports only focused on the geological evolution process [911], the change of biological communities [12-14], and the evolution of the chemical environment in the Mariana Trench [15-17]. Systematic research on the physical and mechanical properties of the sediments in this area is limited. The standard for soil test method [18] is usually used to study the physical and mechanical properties of deep oceanic sediments. Wang et al. [19] used a box corer (BC) and multiple cores (MUC) to carry out indoor experiments on the seafloor sediments in the Clarion-Clipperton Mining Zone of the Pacific Ocean and analyzed the relationship between geotechnical engineering properties and buried depth. Yu et al. [20] sampled 20 columnar deep-sea sediments in the western Pacific Ocean using gravity piston cores (GPC). The results indicated its relatively high water content and low viscosity. 
TABLE 1: The basic information of sediment coring.

\begin{tabular}{|c|c|c|c|c|c|c|c|c|}
\hline & Site & Device & $\begin{array}{c}\text { Core length } \\
\mathrm{cm}\end{array}$ & $\begin{array}{l}\text { Water depth } \\
\text { m }\end{array}$ & $\begin{array}{l}\text { Latitude } \\
\text { N }\end{array}$ & $\begin{array}{l}\text { Longitude } \\
\text { W }\end{array}$ & $\begin{array}{c}\text { Salinity } \\
\%\end{array}$ & $\begin{array}{c}\text { Temperature } \\
{ }^{\circ} \mathrm{C}\end{array}$ \\
\hline \multirow{4}{*}{ Cruise } & MC01 & $\mathrm{MC}$ & 26 & 5455 & $10^{\circ} 50.85^{\prime}$ & $141^{\circ} 57.17^{\prime}$ & 34.69 & 1.53 \\
\hline & $\mathrm{MC} 02$ & MC & 34 & 5481 & $11^{\circ} 45.83^{\prime}$ & $141^{\circ} 58.54^{\prime}$ & 34.69 & 1.54 \\
\hline & GC02 & GC & 86 & 5455 & $11^{\circ} 46.59^{\prime}$ & $141^{\circ} 58.59^{\prime}$ & 34.69 & 1.53 \\
\hline & GC03 & GC & 108 & 5423 & $10^{\circ} 47.60^{\prime}$ & $142^{\circ} 03.30^{\prime}$ & 34.69 & 1.53 \\
\hline \multirow{4}{*}{ TS01 } & B02 & $\mathrm{BC}$ & 58 & 6980 & $10^{\circ} 59.38^{\prime}$ & $141^{\circ} 57.87^{\prime}$ & 34.69 & 1.76 \\
\hline & B08 & $\mathrm{BC}$ & 60 & 7143 & $11^{\circ} 36.13^{\prime}$ & $142^{\circ} 13.70^{\prime}$ & 34.69 & 1.76 \\
\hline & B09 & $\mathrm{BC}$ & 60 & 7121 & $10^{\circ} 59.65^{\prime}$ & $141^{\circ} 59.65^{\prime}$ & 34.69 & 1.76 \\
\hline & B10 & $\mathrm{BC}$ & 60 & 8636 & $11^{\circ} 11.70^{\prime}$ & $141^{\circ} 48.70^{\prime}$ & 34.69 & 2.03 \\
\hline TS03 & GT01 & GC & 361 & 8636 & $11^{\circ} 11.69^{\prime}$ & $141^{\circ} 48.70^{\prime}$ & 34.69 & 2.03 \\
\hline
\end{tabular}

According to Hamilton's study [21], the liquid phase composition of seabed sediments is seawater, and there is also a positive correlation between the salinity and the depth of the seawater. The saltiness of deep-sea water is much higher than that of the shallow sea, and the properties of deep-sea pore water are the same as those of seafloor water. After deep oceanic sediments are dried, the salt is left, which will induce an overestimation of physical and mechanical properties' mineral residue and error. Hence, a method of "salt correction" is necessary.

In this paper, for the first time, we systematically studied the physical and mechanical properties of the oceanic sediment samples in the southwestern part of the Mariana Trench using laser particle size analysis, liquid plastic limit joint determination, consolidation, direct shear, and other geotechnical engineering experimental methods. Combining the advanced scanning electronic microscope (SEM), this study analyzed the relationship between the physical and mechanical properties and the microstructure of the deep oceanic sediments, providing an essential reference for the parameter calibration of numerical simulation and optimization design of the deep-sea mining machine.

\section{Site of Interest}

The "Tan Suo Yi Hao" research vessel carried out scientific research missions in the southwestern area of the Mariana Trench from January 15 to March 24 in 2017. The basic location of sediment samples is concentrated in the Challenger Deep southwest of the Mariana Trench, as shown in Table 1. Deep oceanic sediment samples were obtained by the submersible Jiao Long equipped with box corers (BC), multiple corers (MC), and gravity piston corers (GC) at three depth ranges of $5423 \sim 6010 \mathrm{~m}, 6980 \sim 7143 \mathrm{~m}$, and $8638 \mathrm{~m}$.

The cores were collected using PVC tubes $(9 \mathrm{~cm}$ inner diameter and $70 \mathrm{~cm}$ length), manually inserted into the selected areas under stable temperature [22]. Each PVC tube sample was visually inspected to select undisturbed cores. After sampling, the cores were cut into sections of 1-meter long and then covered and transferred into the sample stor- age room. In order to study more details about the physical and mechanical properties of the oceanic sediments, the cores collected from the $8638 \mathrm{~m}$ seafloor at $141^{\circ} 48.7008^{\prime} \mathrm{E}$, $11^{\circ} 11.6988^{\prime} \mathrm{N}$ southwest of the Mariana Trench were selected for further study, as shown in Figure 1.

\section{Method for Measuring the Physical Properties of Sediments}

A corrected method was proposed to measure the physical properties of the surface sediments at the bottom of the deep sea while considering the soluble salts in the pore water. The composition of deep-sea sediments was introduced for the first time; the liquid is seawater composed of soluble salt and pure water, and the other two parts include soil particle and gas. Figure 2 illustrates the volume and mass of every component in the sediment. The physical property index is defined as follows: "soil" can be represented by the subscript "s," and "salt" is set as "sa." Therefore, the volume of the air, pure water, soil particles, seawater, and pore in the sediments is set as $V_{\mathrm{a}}, V_{\mathrm{w}}, V_{\mathrm{s}}, V_{\mathrm{wsa}}$, and $V_{\mathrm{v}}$, respectively. Similarly, the mass of the air, pure water, soil particles, seawater, and salt in the sediments is set as $m_{\mathrm{a}}, m_{\mathrm{w}}, m_{\mathrm{s}}, m_{\mathrm{wsa}}$, and $m_{\mathrm{sa}}$, respectively. The total mass of salt and residual mineral particles is set as $m_{\mathrm{ssa}}$ in the sediments after drying, and the salt content of seawater is represented as $S_{\mathrm{sa}}$.

Relationships between these indices are expressed as follows.

$$
\begin{gathered}
V_{\mathbf{v}}=V_{\mathbf{a}}+V_{\mathbf{w s a}}, \\
m=m_{\mathbf{s}}+m_{\mathbf{s a}}+m_{\mathbf{w}}, \\
m_{\mathbf{w s a}}=m_{\mathbf{s a}}+m_{\mathbf{w}}, \\
S_{\mathbf{s a}}=\frac{m_{\mathbf{s a}}}{m_{\mathbf{s a}}+m_{\mathbf{w}}} .
\end{gathered}
$$

Hottman [23] defined the water content of the deep oceanic sediments, as shown in the following formula. 


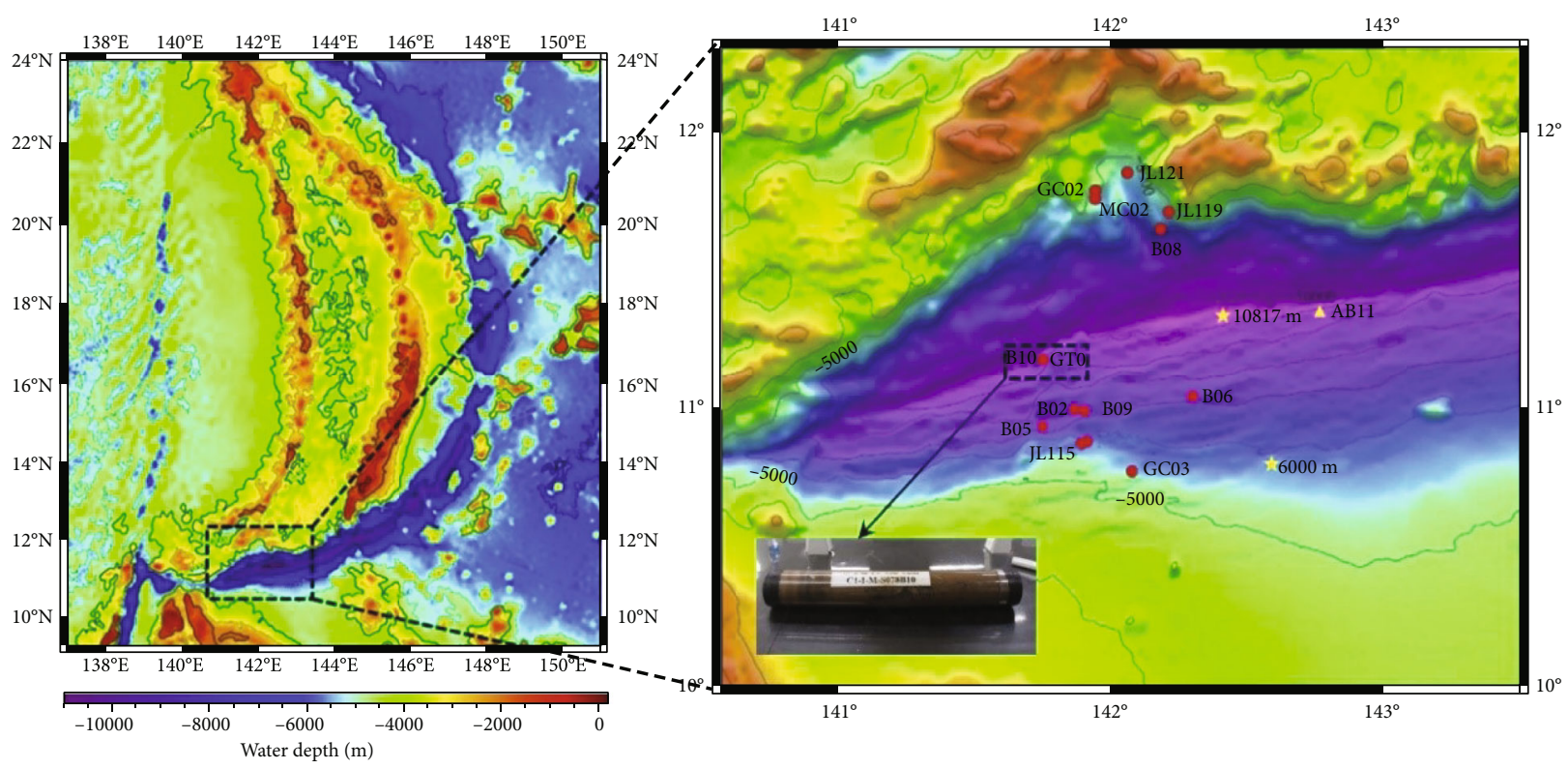

FIgURE 1: Bathymetric map of the southern Mariana Trench and the sampling location of this study.
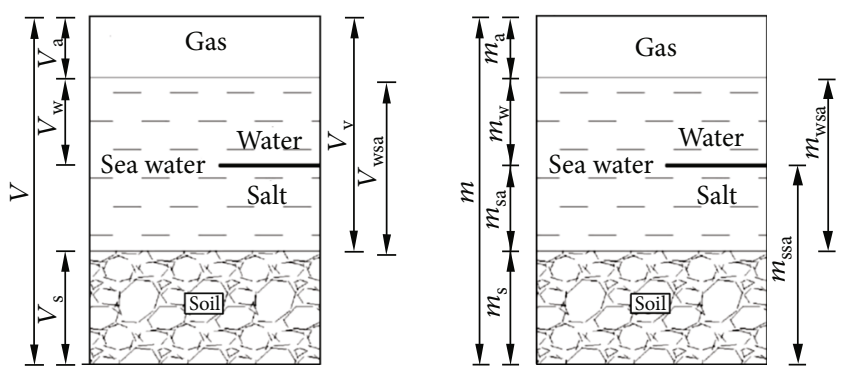

Figure 2: Calculation model of deep-sea sediment.

$$
\begin{aligned}
& \frac{\text { Mass of liquid }}{\text { Mass of soil particles }} \\
& =\frac{\text { Mass of sea water in the soil }}{\text { Mass of solid particles - Mass of salt }} .
\end{aligned}
$$

Combined with the characteristics of the deep-sea sediments, a modified method for measuring its water content was proposed. According to the standard for soil test method [18] (GB/T50123-1999), when the salt in the pore water is not taken into account, the water content " $w$ " can be calculated as follows.

$$
w=\frac{m_{\mathbf{w}}}{m_{\mathbf{s a}}+m_{\mathbf{s}}} .
$$

However, because the salt was left after drying the sediment, combining with Hottman's proposal [23], the corrected water content " $w_{\mathrm{c}}$ " of the sediments should be given as follows by taking the salt into account.

$$
w_{\mathbf{c}}=\frac{m_{\mathbf{w}}+m_{\mathbf{s a}}}{m_{\mathbf{s}}} .
$$

Then, based on formulas (4), (6), and (7), it can be inferred that the relationship between the water content " $w_{\mathrm{c}}$ " and " $w$ " conforms to a certain law, as shown in

$$
\begin{aligned}
w & =\frac{1-S_{\mathrm{sa}}}{\left(1 / w_{\mathrm{c}}\right)+S_{\mathrm{sa}}}, \\
w_{\mathrm{c}} & =\frac{1}{\left(\left(1-S_{\mathrm{sa}}\right) / w\right)-S_{\mathrm{sa}}} .
\end{aligned}
$$

According to the standard for soil test method [18], the specific gravity " $G_{s}$ " of the sediments can be measured as follows without considering the salt in the pore water:

$$
G_{\mathrm{s}}=\frac{m_{\mathrm{ssa}}}{m_{\mathrm{bw}}+m_{\mathrm{ssa}}-m_{\mathrm{bws}}} \times G_{\mathrm{iT}} .
$$

The mass of the pycnometer and water is set as $m_{\mathrm{bw}}$; the mass of the pycnometer and water and solid particles is set as $m_{\text {bws }}$; the specific gravity of the pure water at $\mathrm{T}^{\circ} \mathrm{C}$ is set as $G_{\mathrm{iT}}$.

Combining with Hottman's proposal [23], the corrected specific gravity " $G_{\mathrm{sc}}$ " of the sediments can be given as follows considering the salt in the pore water.

$$
G_{\mathrm{sc}}=\frac{m_{\mathrm{ssa}}-m_{\mathrm{sa}}}{m_{\mathrm{bw}}+m_{\mathrm{ssa}}-m_{\mathrm{bws}}} \times G_{\mathrm{iT}}
$$

Then, using equation (10) and the following equations (12)-(15),

$$
\begin{gathered}
w_{\mathrm{c}} \times S_{\mathrm{sa}}=\frac{m_{\mathrm{sa}}}{m_{\mathrm{s}}}, \\
m_{\mathrm{ssa}}=m_{\mathrm{sa}}+m_{\mathrm{s}} .
\end{gathered}
$$


TABLE 2: Water content before and after correction.

\begin{tabular}{lccccccc}
\hline Groups & 1 & 2 & 3 & 4 & 5 & 6 & Mean value \\
\hline Water content without considering salt, $w(\%)$ & 201.22 & 203.85 & 202.52 & 199.70 & 198.46 & 204.22 & 201.67 \\
Water content considering salt, $w_{\mathrm{c}}(\%)$ & 224.71 & 227.87 & 226.26 & 222.87 & 221.38 & 228.31 & 225.23 \\
\hline
\end{tabular}

TABLE 3: Specific gravity before and after correction.

\begin{tabular}{|c|c|c|c|c|c|c|c|}
\hline Groups & $\begin{array}{c}\text { Temperature } \\
\left({ }^{\circ} \mathrm{C}\right)\end{array}$ & $\begin{array}{c}\text { Water } \\
\text { specific } \\
\text { gravity, } G_{\mathrm{iT}}\end{array}$ & $\begin{array}{l}\text { Mass of solid } \\
\text { particles, } m_{\text {ssa }} \\
\text { (g) }\end{array}$ & $\begin{array}{l}\text { Mass of the } \\
\text { pycnometer and } \\
\text { water, } m_{\mathrm{bw}}(\mathrm{g})\end{array}$ & $\begin{array}{l}\text { Mass of the pycnometer and } \\
\text { water and solid particles, } m_{\mathrm{bws}} \\
\text { (g) }\end{array}$ & $\begin{array}{l}\text { Measured } \\
\text { specific } \\
\text { gravity, } G_{\mathrm{s}}\end{array}$ & $\begin{array}{l}\text { Corrected } \\
\text { specific } \\
\text { gravity, } G_{\mathrm{sc}}\end{array}$ \\
\hline 1 & 20.5 & 0.998128 & 3.182 & 79.68 & 81.699 & 2.7309 & 2.5227 \\
\hline 2 & 20.5 & 0.998128 & 3.181 & 79.679 & 81.702 & 2.7513 & 2.5410 \\
\hline
\end{tabular}

Based on

$$
\begin{gathered}
m_{\mathrm{sa}}=\frac{m_{\mathrm{ssa}}}{1+\left(1 /\left(w_{\mathrm{c}} \times S_{\mathrm{sa}}\right)\right)}, \\
m_{\mathrm{ssa}}-m_{\mathrm{sa}}=\left(1-\frac{1}{1+\left(1 /\left(w_{\mathrm{c}} \times S_{\mathrm{sa}}\right)\right)}\right) \times m_{\mathrm{ssa}},
\end{gathered}
$$

the relationship between the specific gravity " $G_{\mathrm{s}}$ ” and the corrected specific gravity " $G_{\mathrm{sc}}$ ” is obtained as

$$
G_{\mathrm{sc}}=\left(1-\frac{1}{1+\left(1 /\left(w_{\mathrm{c}} \times S_{\mathrm{sa}}\right)\right)}\right) \times G_{\mathrm{s}} .
$$

\section{Results and Discussion}

4.1. Physical and Mechanical Properties of Deep-Sea Sediments. The physical and mechanical properties of materials will affect their deformation under load. Unlike terrigenous sediment, the sedimentation rate of the deep oceanic sediments is usually prolonged. The deep-sea sediments are mainly formed in the environment of continental steps at the bottom of the sea, deep-sea hills, and deep-sea plain where the water temperature is $1^{\circ} \mathrm{C} \sim 4^{\circ} \mathrm{C}$ below 4800 6000 $\mathrm{m}$ [24]. According to Hamilton [21], there is a positive correlation between the salt content $S_{\text {sa }}$ and depth $H$ when the seawater is within the depth of $6000 \mathrm{~m}$. However, when the seawater is beyond $6000 \mathrm{~m}$, the salt content $S_{\text {sa }}$ will no longer vary with the depth of the seawater $H$; at this time, the salt content of the seawater $S_{\mathrm{sa}}$ is $3.469 \%$, and the density of the corresponding seawater $\rho_{\text {wsa }}$ is $1.02372 \mathrm{~g} / \mathrm{cm}^{3}$ [25]. As shown in Table 1, the salt content and density of the seawater cored from the Challenger Deep in the Mariana Trench also conform to this law. For the deep oceanic sediments, its transfer will not change the salt content in the pore water. Therefore, the following assumptions can be made: (1) the mass of the air in the sediments can be ignored; (2) the volume of the seawater is the same as that of pure water of the same mass; (3) the salt content $S_{\mathrm{sa}}$ of the pore water in the deep oceanic sediments is $3.469 \%$, and its density $\rho_{\text {wsa }}$ is $1.02372 \mathrm{~g} / \mathrm{cm}^{3}$. Then, the physical properties of the deep-sea sediment samples were measured.
4.2. Density. According to the standard for soil test method [18], two parallel tests measuring the density with the ring knife method were designed. The results were $\rho_{1}=1.2501 \mathrm{~g}$ $/ \mathrm{cm}^{3}$ and $\rho_{2}=1.2480 \mathrm{~g} / \mathrm{cm}^{3}$, respectively. The mean value $\rho$ $=1.249 \mathrm{~g} / \mathrm{cm}^{3}$ was taken as the density of the deep-sea sediments in this area.

4.3. Water Content. Firstly, six groups of sediment samples were taken from the PVC tube. Secondly, each sample was tested to measure the water content " $w$ ". Finally, according to formula (9), the corrected water content " $w_{c}$ " can be calculated using " $w$ " and " $S_{\mathrm{sa}}$ ", as listed in Table 2 . The average value of the fixed water content " $w_{\mathrm{c}}$ " of these six groups of samples was $225.23 \%$, which was regarded as the water content of the sediments in these sea areas.

4.4. Specific Gravity. Hottman [23] proposed a method for measuring the specific gravity of deep-sea sediments. The soil particles and dried salt are repeatedly washed, filtered, and dried to remove the crystalline salt. After repeating many times, the left solids are all soil particles. At this time, the specific gravity of soil particles in the sediments can be measured. However, due to the loss of some tiny soil particles in that process, the measured specific gravity is different from the actual value. Therefore, a corrected method was proposed to avoid this error based on the characteristic of the deep oceanic sediments in this area. Firstly, two groups of sediment samples were taken from the PVC tube. Secondly, each sample was tested to measure the specific gravity " $G_{s}$ ”. Finally, according to formula (16), the corrected specific gravity " $G_{\text {sc }}$ " can be calculated by " $G_{s}$ " and " $S_{\text {sa }}$ " as shown in Table 3. The average value of the corrected specific gravity " $G_{\text {sc }}$ " was 2.53 , which was regarded as the specific gravity of the sediments in this area.

4.5. Particle Diameter. The Winner 2000ZDE Automatic Laser Diffraction Particle Size Analyzer was used to measure the particle diameter. In this experiment, five groups of sediment samples were taken from the PVC tube to test their particle diameter and take the mean value for analysis. Figure 3 shows the relationship between the particle diameter $(\lg d)$ and cumulative mass $(M)$, and Figure 4 shows the relationship between the particle diameter $(\lg d)$ and frequency 


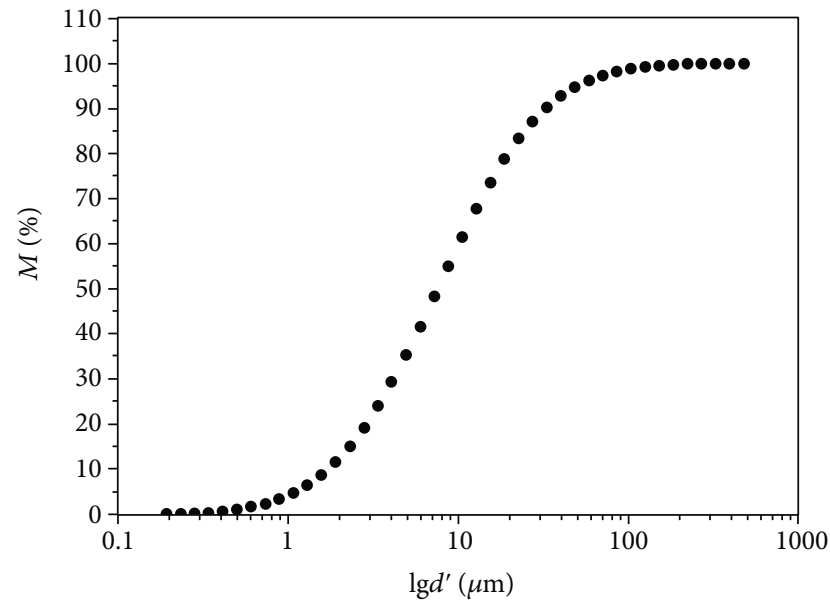

Figure 3: Particle diameter $d$ and cumulative mass $M$ curve.

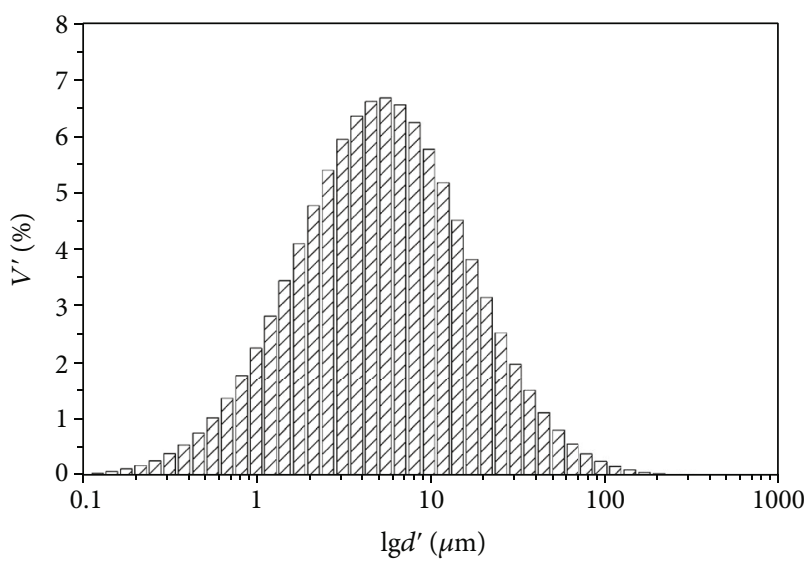

Figure 4: Particle diameter $d$ and volume frequency $V$ curve.

$(V)$ curve. The particle diameter $d$ is usually expressed in the form of logarithm; $M$ represents the percentage of the total mass of the sediments with a certain diameter less than a certain diameter; $V$ is the percentage of the volume of the sediments with different particle diameters.

The particle diameters of the samples range from $0.4 \mu \mathrm{m}$ to $78.995 \mu \mathrm{m}$, which are mainly composed of fine sand $(0.25 \mathrm{~mm} \leq d \leq 0.3 \mathrm{~mm})$, extremely fine sand $(0.075 \mathrm{~mm} \leq d \leq 0.25 \mathrm{~mm})$, silt $(0.005 \mathrm{~mm} \leq d \leq 0.075 \mathrm{~mm})$, clay $(d \leq 0.005 \mathrm{~mm})$, and colloidal particles $(d \leq 0.002 \mathrm{~mm})$. According to Figure 4, the volume percentage of each component is $1.15 \%$ of sand, $50.47 \%$ of silt, $48.38 \%$ of clay, and $19.29 \%$ of colloidal particles. It is indicated that the sediments are mainly composed of silt and clay. Among them, the silt has low water permeability, slight viscosity, and a large-rise height of capillary water; clay also has low water permeability and shows viscosity and plasticity. Therefore, the sediments behave with the characteristics of plasticity, low water permeability, and high water content. Although the sand has the characteristics of high permeability, no viscosity, and small-rise height of capillary water, the little content makes its effect be ignored.

Based on Figure 3, the particle diameters $d$, the median of particle diameters $d_{50}$, the effective particle diameters $d_{10}$, the
TABLE 4: Different particle diameter indices of the sediments.

\begin{tabular}{lcccc}
\hline $\begin{array}{l}\text { Particle } \\
\text { diameters, } \\
d(\mu \mathrm{m})\end{array}$ & $\begin{array}{c}\text { The median } \\
\text { of particle } \\
\text { diameters, } \\
d_{50}(\mu \mathrm{m})\end{array}$ & $\begin{array}{c}\text { Effective } \\
\text { particle } \\
\text { diameters, } \\
d_{10}(\mu \mathrm{m})\end{array}$ & $\begin{array}{c}\text { Continuous } \\
\text { particle } \\
\text { diameters, } \\
d_{30}(\mu \mathrm{m})\end{array}$ & $\begin{array}{c}\text { Control of } \\
\text { particle } \\
\text { diameters, } \\
d_{60}(\mu \mathrm{m})\end{array}$ \\
\hline $0.1 \sim 78.995$ & 5.340 & 1.024 & 2.733 & 6.256 \\
\hline
\end{tabular}

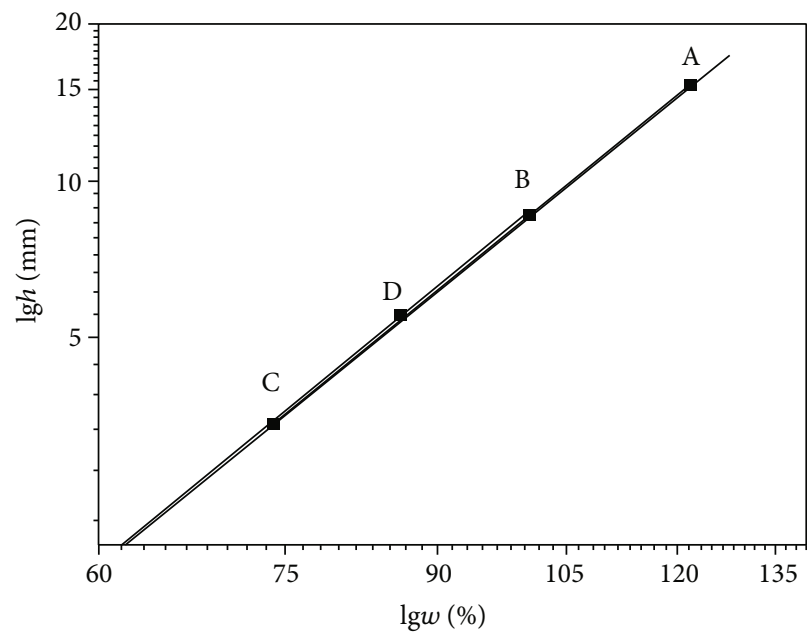

FIGURE 5: Relationship of cone sinking depth and water content.

continuous particle diameters $d_{30}$, and the control particle diameters $d_{60}$ of the sediments from the southwestern part of the Challenger Deep in the Mariana Trench were calculated, as shown in Table 4. The nonuniformity coefficient $C_{\mathrm{u}}$ and curvature coefficient $C_{\mathrm{c}}$ of the deep-sea sediment samples are calculated as follows:

$$
\begin{gathered}
C_{\mathrm{u}}=\frac{d_{60}}{d_{10}}=6.1, \\
C_{\mathrm{c}}=\frac{d_{30}^{2}}{d_{10} \times d_{60}}=1.17 .
\end{gathered}
$$

Since $C_{\mathrm{u}}=6.1 \geq 5$, it can be known that this sediment contains particles of different thicknesses, which can be categorized into heterogeneous soils. Figure $3 \mathrm{can}$ also indicate that the sediment has a good gradation as the curvature coefficient $C_{\mathrm{c}}$ is 1.17 .

4.6. Liquid Limit and Plastic Limit. The TKA-YSY-1 digital soil liquid-plastic limit analyzer was used to measure the liquid limit and plastic limit of the samples. The instrument is suitable for sediments with a particle size of less than $0.5 \mathrm{~mm}$ and sediments whose organic matter content is not more than $5 \%$ of the total sample. Firstly, the average water content of three groups of undisturbed sediment samples was measured $w_{0}=225.1 \%$. Then, the sample with natural water content is dried, fully stirred, and filled into the sample cup. Finally, the penetration depth $h$ for water content $w$ of $73.9 \%, 100.49 \%$, and $121.9 \%$ was measured to be $3.4 \mathrm{~mm}$, $8.6 \mathrm{~mm}$, and $15.3 \mathrm{~mm}$, respectively, as shown in Figure 5. 


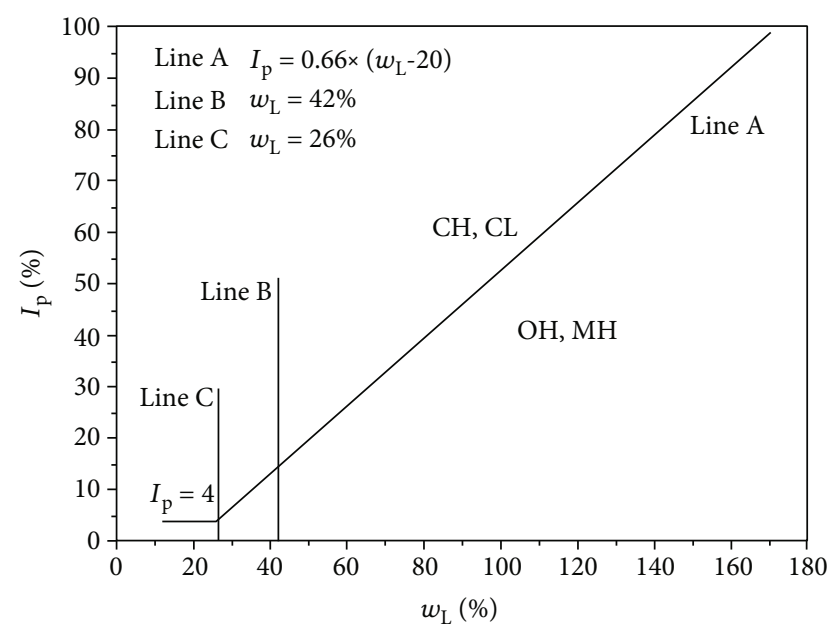

Figure 6: Casagrande plasticity of deep-sea sediments.

According to the method in literature [18], points A and point $\mathrm{B}$ were connected and extended to determine the water content $w_{\mathrm{AB}}=62.9 \%$ at $h=2 \mathrm{~mm}$; point $\mathrm{A}$ and point $\mathrm{C}$ are connected and extended to determine the water content $w_{\mathrm{AC}}=63.6 \%$ at $h=2 \mathrm{~mm}$. The difference between the water content of $w_{\mathrm{AB}}$ and $w_{\mathrm{AC}}$ is $\Delta w=0.7 \%<2 \%$, meeting the requirements in the standard. Find point $\mathrm{D}$ in the middle of points $\mathrm{B}$ and $\mathrm{C}$ and connect it to point $\mathrm{A}$ to form a line. Thus, the liquid limit $w_{\mathrm{L}}$ is determined as the water content corresponding to the sinking depth of $17 \mathrm{~mm}$. Similarly, when the sinking depth of the cone is $2 \mathrm{~mm}$, the corresponding water content is called plastic limited $w_{\mathrm{p}}$. As shown in Figure 5, the liquid limit $w_{\mathrm{L}}$ of the deep-sea sediment is $133.1 \%$, and the plastic limit $w_{\mathrm{p}}$ is $63.4 \%$. It can be known that the plasticity index $I_{\mathrm{p}}$ and the liquidity index $I_{\mathrm{L}}$ are as follows.

$$
\begin{aligned}
& I_{\mathrm{p}}=\left(w_{\mathrm{L}}-w_{\mathrm{p}}\right) \times 100=69.4, \\
& I_{\mathrm{L}}=\frac{w_{\mathrm{c}}-w_{\mathrm{p}}}{w_{\mathrm{L}}-w_{\mathrm{p}}}=2.33 .
\end{aligned}
$$

The sediment sample $I_{\mathrm{p}}=69.4$ indicates that the water content in the plastic state varies widely, and the content of hydrophilic minerals in the soil is high. The sediment sample $I_{\mathrm{L}}=2.33>1$ indicates that the sediment is soft and fluid, which means that the sediment is flowable.

It can be seen from Figure 6 that the sediment samples are classified according to the Casagrande plasticity chart. According to the measured liquid limit $w_{\mathrm{L}}$ and plasticity index $I_{\mathrm{p}}$, it can be known that the sediment sample is distributed in the $\mathrm{MH}, \mathrm{OH}$ areas of the Casagrande plasticity chart and the sediments are made up of high liquid limit silt, organic clay, and organic silt. According to Section 4.5, the proportion of silt is as high as $50.47 \%$. Therefore, it can be inferred that the sediments mainly consist of highly absorbent minerals.

In order to indicate the ability to absorb bound water of clay mineral in sediments, the activity index $A$ of the sediment is calculated as follows.
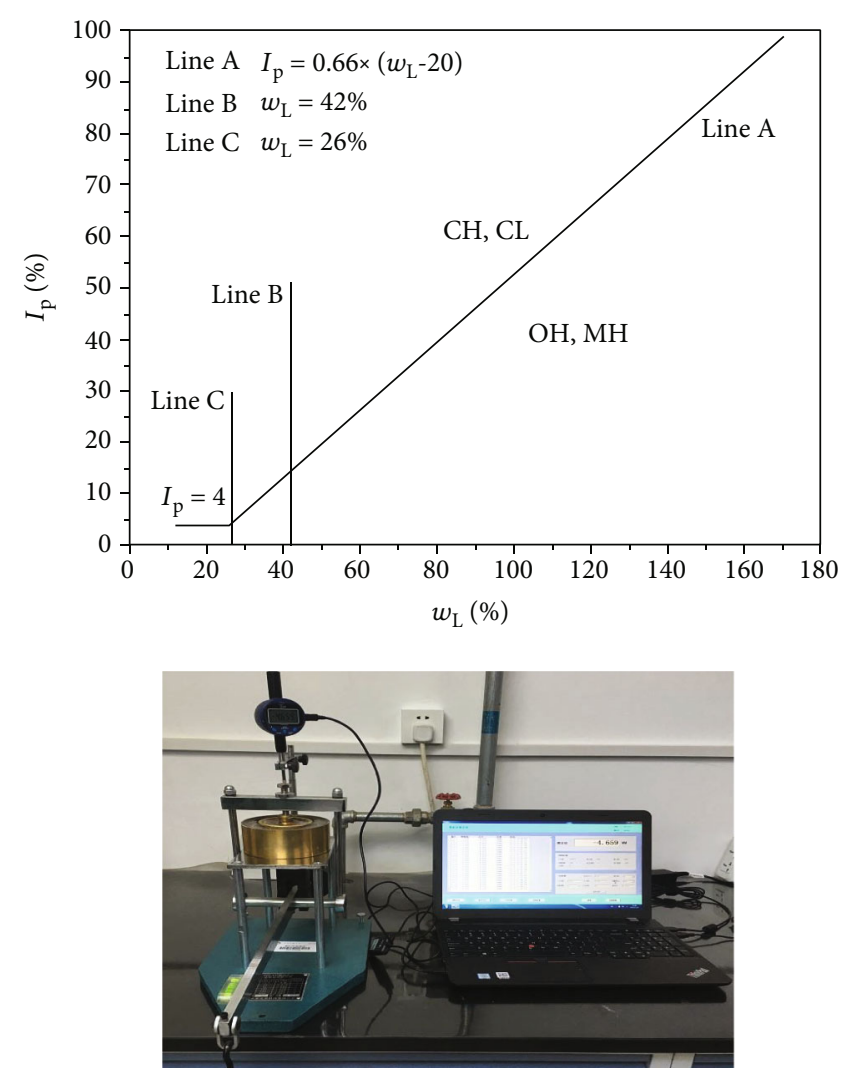

FIgURE 7: Consolidation apparatus of K0.

$$
A=\frac{I_{\mathrm{p}}}{P_{0.002}}=\frac{69.5}{19.29}=3.60,
$$

where $P_{0.002}$ is the mass percentage of particles with a particle diameter $d<0.002 \mathrm{~mm}$; it can be known from $A>$ 1.25 that the sediment is activated clay, among which the clay minerals are mainly composed of montmorillonite with strong water absorption capacity.

4.7. Compression Modulus. The K0 consolidation instrument used in this experiment was improved and designed concerning the American Stuetral Behavior Engineering Laboratories K0 tester, as shown in Figure 7. The compression coefficient $a_{\mathrm{v}}$ and compression modulus $E_{\mathrm{s}}$ of the undisturbed sediments from the Challenger Deep in the Mariana Trench were determined by consolidation test. According to the measured average density $\rho=1.249 \mathrm{~g} / \mathrm{cm}^{3}$ and specific gravity $G_{\mathrm{sc}}=$ 2.53 , the initial porosity $e_{0}$ of the sediment can be obtained as follows.

$$
e_{0}=\frac{\left(1+\omega_{0}\right) G_{\mathrm{s}} \rho_{\mathrm{w}}}{\rho}-1=5.58,
$$

where $\rho_{\mathrm{w}}=1.00 \mathrm{~g} / \mathrm{cm}^{3}$ is the density of pure distilled water at $4^{\circ} \mathrm{C}$.

During the test, pressure $p(12.5,25,50,100,200$, and $400 \mathrm{kPa}$ ) was applied in sequence to conduct a consolidation test, and each loading was kept for $24 \mathrm{~h}$. After the 
TABLe 5: Consolidation test parameters.

\begin{tabular}{lccccccc}
\hline $\begin{array}{l}\text { Pressure, } \\
p(\mathrm{kPa})\end{array}$ & $\begin{array}{c}\text { Pressure } \\
\text { variation, } \Delta p \\
(\mathrm{kPa})\end{array}$ & $\begin{array}{c}\text { Deformation, } \\
\Delta h(\mathrm{~mm})\end{array}$ & $\begin{array}{c}\text { Total deformation, } \\
\Delta h \sum \Delta h(\mathrm{~mm})\end{array}$ & $\begin{array}{c}\text { Void } \\
\text { ratio, } e\end{array}$ & $\begin{array}{c}\text { Void ratio } \\
\text { variation, } \Delta e\end{array}$ & $\begin{array}{c}\text { Compression } \\
\text { coefficient, } a_{\mathrm{v}} \\
\left(\mathrm{MPa}^{-1}\right)\end{array}$ & $\begin{array}{c}\text { Compression } \\
\mathrm{modulus}, E_{\mathrm{s}}(\mathrm{MPa})\end{array}$ \\
\hline 12.5 & 12.5 & 1.485 & 1.485 & 5.094 & 0.489 & 39.120 & 0.017 \\
25.5 & 12.5 & 1.456 & 2.941 & 4.615 & 0.479 & 38.339 & 0.173 \\
50 & 25 & 1.717 & 4.658 & 4.050 & 0.565 & 22.606 & 0.294 \\
100 & 50 & 1.601 & 6.259 & 3.523 & 0.527 & 10.539 & 0.630 \\
200 & 100 & 1.678 & 7.937 & 2.971 & 0.552 & 5.523 & 1.202 \\
\hline
\end{tabular}

consolidation was completed, the deformation amount $\Delta h$ and the pressure increase $\Delta p$ at each level were recorded. The total deformation amount $\Sigma \Delta h$ can be obtained by accumulating the deformation amount $\Delta h$ at each pressure, where $\Delta e$ is the change in the porosity $e$ under each increase of pressure. Table 5 shows the porosity $e$, compression coefficient $a_{\mathrm{v}}$ , and compression modulus $E_{\mathrm{s}}$ calculated from equations (21)-(23). Figure 8 shows the $e-p$ curves, and Figure 9 shows the $e$ - $\lg p$ curves.

$$
\begin{aligned}
& e=e_{0}-\frac{1+e_{0}}{h_{0}} \sum \Delta h, \\
& a_{\mathrm{v}}=\frac{\Delta e}{\Delta p}, \\
& E_{\mathrm{s}}=\frac{1+e_{0}}{a_{\mathrm{v}}} .
\end{aligned}
$$

Compression coefficient $a_{\mathrm{v}}$ is the steepness of the e-p curve, which represents the reduction of the porosity ratio caused by the pressure increase. It also can represent the compressibility of the undisturbed sediment, as shown in Figure 8. In actual engineering, the compression coefficient $a_{\mathrm{v} 1-2}$ corresponding to the pressure range of $100 \sim 200 \mathrm{kPa}$ is generally used to evaluate the compressibility of soil. If $a_{\mathrm{v} 1-2}$ $<0.1 \mathrm{MPa}^{-1}$, the sediment can be called a lowcompressibility soil. If $0.1 \mathrm{MPa}^{-1} \leq a_{\mathrm{v} 1-2}<0.5 \mathrm{MPa}^{-1}$, it can be called medium-compression soil. If $a_{\mathrm{v} 1-2} \geq 0.5 \mathrm{MPa}^{-1}$, it can be called high-compression soil. For the sediment samples in this paper, $a_{\mathrm{v} 1-2}$ is $5.523 \mathrm{MPa}^{-1}$ and $E_{\mathrm{s} 1-2}$ is 1.202 MPa, so it belongs to highly compressive sediments.

The compression index $C_{c}$ and the compression coefficient $a_{\mathrm{v}}$ have the same variation trend. As the compression index $C_{\mathrm{c}}$ of the sediment becomes larger or the compression coefficient $a_{\mathrm{v}}$ of the sediment becomes larger, the compressibility of the sediment becomes higher. The $C_{c}$ value of low-compressibility sediments is generally less than 0.2 , and the $C_{c}$ value of high-compressibility sediments is generally greater than 0.4 .

The solution for the sediment compression index $C_{\mathrm{c}}$ is to take a long approximate straight line after the semilogarithmic compression curve. The slope of this line represents the

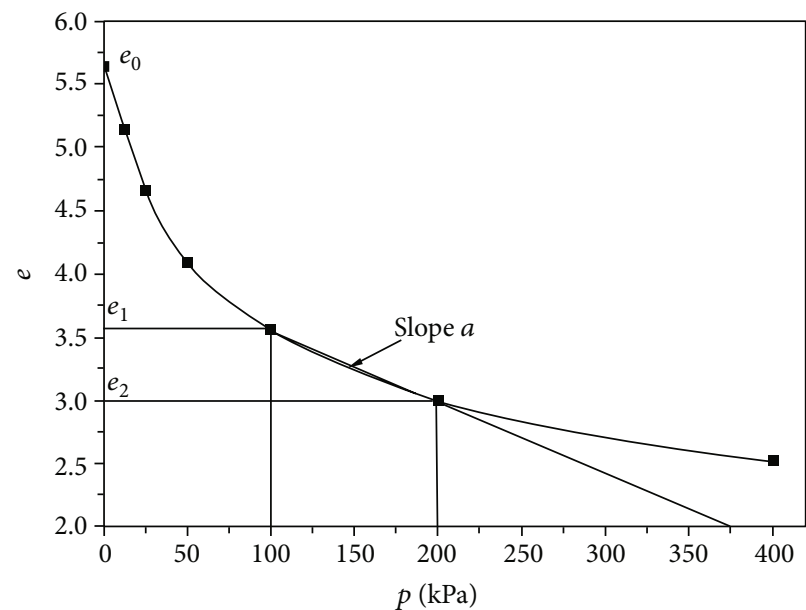

Figure 8: The $e-p$ curve and the determination of compression coefficient $a_{\mathrm{v}}$ of soil.

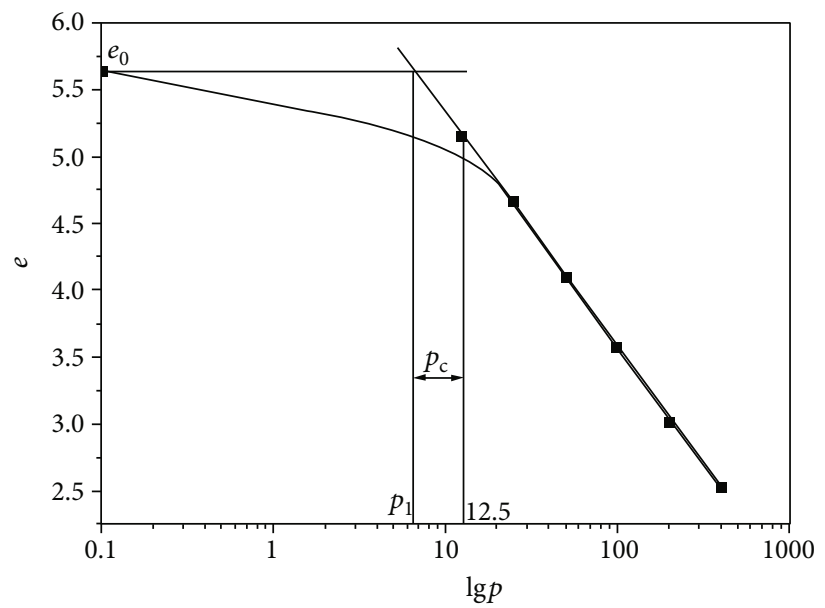

Figure 9: The $e-\lg p$ curve and compression index $C_{\mathrm{c}}$ of soil.

soil compression index, as shown in

$$
C_{\mathrm{c}}=-\frac{\Delta e}{\lg p}=\frac{e_{1}-e_{2}}{\lg p_{2}-\lg p_{1}}=-\frac{\Delta e}{\lg \left(p_{2} / p_{1}\right)} .
$$

According to the above formula, the compression index $C_{\mathrm{c}}$ of the undisturbed sediments was calculated to be 1.733 $>0.4$, belonging to compressible sediment. Figure 9 shows that the value of the early consolidation pressure $p_{c}$ of the sediments in the area is between $p_{1}$ and $12.5 \mathrm{kPa}$. The reason 


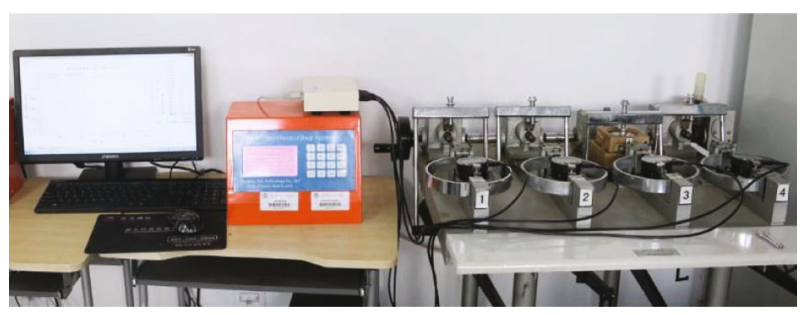

FIGURE 10: Strain control-type direct shear instrument.

is that the sediments are relatively thin and soft; they also have a large compressive deformation under the initial load of $12.5 \mathrm{kPa}$, which makes the $e--\lg p$ curve appear a straight line segment without inflexion at the stage after $12.5 \mathrm{kPa}$.

4.8. Shear Strength. The ZJ quadruple strain-controlled direct shear instrument produced by Nanjing Soil Instrument Co. Ltd. was introduced to test the shear strength of the undisturbed sediments in the Challenger Deep of Mariana Trench, as shown in Figure 10. Firstly, 4 sediment samples were taken with a ring knife. Secondly, 4 different vertical pressures $p$ $(50,100,200,300$, and $400 \mathrm{kPa})$ were applied, respectively. Thirdly, after removing the fixed pin, shear stress $\tau$ can be applied to the samples by means of displacement loading at the speed of $0.8 \mathrm{~mm} / \mathrm{min}$, where the deep-sea sediment samples will be damaged in $3 \sim 5 \mathrm{~min}$.

The area of the shear $A_{0}$ is $30 \mathrm{~cm}^{2}$. Corresponding to the vertical pressure of $50 \mathrm{kPa}, 100 \mathrm{kPa}, 200 \mathrm{kPa}$, and $300 \mathrm{kPa}$, the maximum displacement value is $R_{50}=2.2 \mathrm{~mm}, R_{100}=2.6$ $\mathrm{mm}, R_{200}=3.8 \mathrm{~mm}$, and $R_{300}=4.5 \mathrm{~mm}$, respectively. When the vertical load reached $400 \mathrm{kPa}$, a sediment sample was extruded from the earth pressure box. Based on this experiment, the shear stresses $\tau_{50}$ for $p=50 \mathrm{kPa}, \tau_{100}$ for $p=100$ $\mathrm{kPa}, \tau_{200}$ for $p=200 \mathrm{kPa}$, and $\tau_{300}$ for $p=300 \mathrm{kPa}$ are as follows.

$$
\begin{gathered}
\tau_{50}=\frac{T_{50} \times R_{50}}{A_{0}} \times 10=18.26(\mathrm{kPa}), \\
\tau_{100}=\frac{T_{100} \times R_{100}}{A_{0}} \times 10=21.58(\mathrm{kPa}), \\
\tau_{200}=\frac{T_{200} \times R_{200}}{A_{0}} \times 10=31.54(\mathrm{kPa}), \\
\tau_{300}=\frac{T_{300} \times R_{300}}{A_{0}} \times 10=40.94(\mathrm{kPa}),
\end{gathered}
$$

where $T_{50}, T_{100}, T_{200}$, and $T_{300}$ are calibration coefficients of the dynamometer.

Figure 11 shows the fitted experimental $\tau$ - $\sigma$ curve. According to the intercept on the $y$-axis, the cohesion $c$ of the deep-sea sediment can be obtained as $13.06 \mathrm{kPa}$. The slope of the straight line indicates that the internal friction angle $\varphi$ of the deep-sea sediment is $5.384^{\circ}$.

Table 6 shows the physical and mechanical parameters of the undisturbed sediments from the Challenger Deep in Mariana Trench and other sediments, such as general cohesive soil, newly deposited cohesive soil, and coastal silty soil

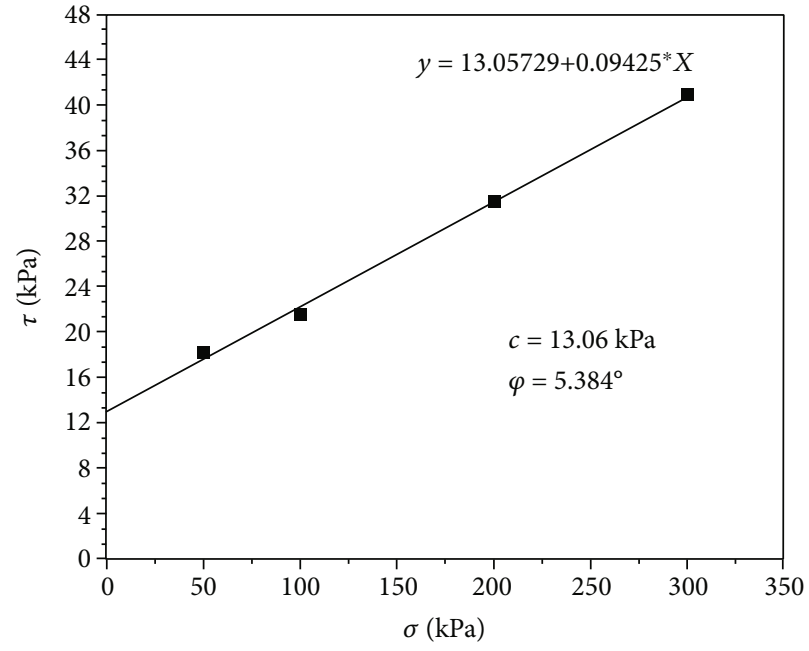

Figure 11: The curve of shear strength and vertical pressure.

[26]. By comparison, it was indicated that the sediment in this area is characterized by large porosity, high water content, high liquid limit, high plasticity index, high liquidity index, low cohesion, and small internal friction angle. Therefore, the deep-mining machines are easy to sink and slip while working on the sediment.

4.9. Microstructure. Through the study of the deep-sea sediment samples from the Challenger Deep in the southwestern part of the Mariana Trench, its properties were investigated. To better understand the relationship between its unique macroscopic physical and mechanical properties and its microstructure, the SEM was used for further study.

The microstructure of the deep-sea sediments was analyzed by Zeiss Merlin FIB high-performance field SEM produced in Germany. Considering high water content and the unstable microstructure of the sediments, the samples were treated by liquid nitrogen freezing and drying method in advance [27]. The undisturbed sediment sample in the middle of the PVC tube was taken with a small spoon and then rapidly transferred to the liquid nitrogen at $-196^{\circ} \mathrm{C}$ until the sample did not produce bubbles (Figure 12(a)). The undisturbed fresh structural surfaces can be obtained by breaking off the freeze-dried samples, which can be used as observation surfaces by SEM (Figure 12(b)). The observed fresh sediment samples were moved to the sample table and dried (Figure 12(c)). Carbon was sprayed onto the sediment surfaces to increase its conductivity, as shown in Figure 12(d). Finally, the prepared sediment samples were sent to the SEM for observation. Figure 13 shows the three SEM images selected for further analysis.

As shown in Figure 13(a), it was found that the deep-sea sediments mainly consisted of a large number of clay minerals, silt, and microbial detritus and the microstructure was mainly composed of flocculation (zone B), with a large number of diatom debris and empty shells of organism around it (zone A). The flocculation is made up of silt and clay, which is mainly composed of soft sediments characterized by the short distance contact between the point-like 
TABLE 6: Physicomechanical property parameters of different origin clays.

\begin{tabular}{lccccccc}
\hline Type of soil & $e$ & $w(\%)$ & $w_{\mathrm{L}}(\%)$ & $I_{\mathrm{p}}$ & $I_{\mathrm{L}}$ & $c(\mathrm{kPa})$ & $\varphi\left(^{\circ}\right)$ \\
\hline General clay soil & $0.55 \sim 1.00$ & $15 \sim 30$ & $25 \sim 45$ & $5 \sim 20$ & $0.0 \sim 0.1$ & $10 \sim 50$ & $15.0 \sim 22.0$ \\
Newly deposited clay & $0.70 \sim 1.20$ & $24 \sim 36$ & $30 \sim 45$ & $6 \sim 18$ & $0.3 \sim 1.2$ & $10 \sim 20$ & $7.0 \sim 15.0$ \\
Coastal silty soil & $1.00 \sim 2.00$ & $36 \sim 70$ & $30 \sim 65$ & $10 \sim 25$ & $>1.0$ & $5 \sim 15$ & $4.0 \sim 10.0$ \\
Deep-sea sediments & 6.03 & 246.2 & 145.2 & 57.0 & 2.15 & 12.6 & 3.1 \\
\hline
\end{tabular}

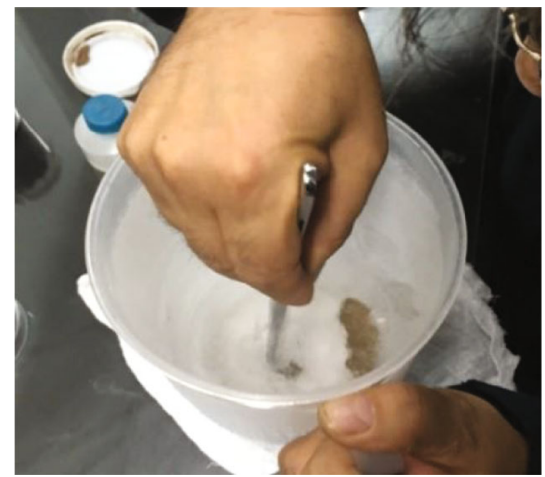

(a)

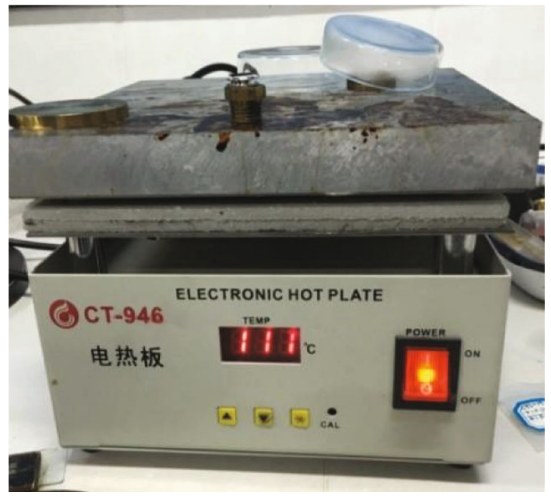

(c)

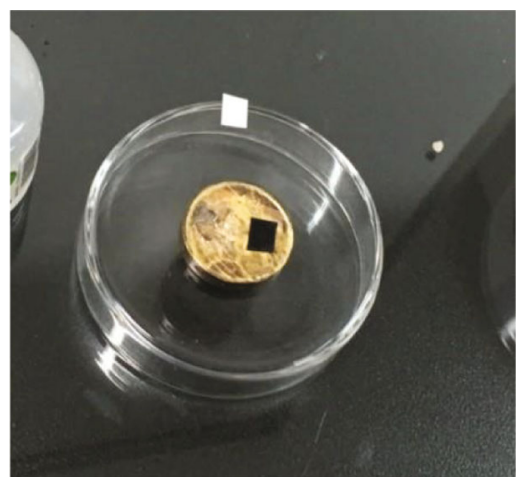

(b)

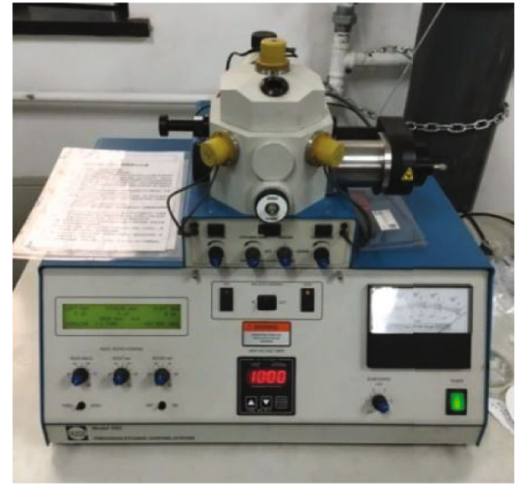

(d)

Figure 12: The preparation process of observation soil sample. (a) The deep-sea soil samples were frozen with liquid nitrogen. (b) The undisturbed fresh structural surfaces can be obtained by breaking off the freeze-dried samples. (c) The observed fresh sediment samples were moved to the sample table and dried. (d) Carbon was sprayed onto the sediment surfaces.

particles and flaky flocculates. Cotton-like flocculation can be observed under the 10000 times magnification [28]. Generally speaking, the sediments are mainly made up of flat particles, which are relatively dense and have some pores (zone D). The tiny granules are mainly contacted in forms of surface to surface, edge to edge [29]. When region A was magnified 2000 times, the diatom fragments were found to contain a large number of pores and arranged in layers (Figure 13(b)). The surface of the diatom fragment contained a large number of small particles (zone C). According to the energy spectrum analysis, the substances mainly contained in it were $\mathrm{NaCl}, \mathrm{MgCl}_{2}$, and $\mathrm{SiO}_{2}$; this is because, after the prepared samples, the internal soluble salt and even smaller diatom debris were left on the surface of the soil samples, which further indicate that some salt exists in the pore water of the deep oceanic sediments. Since the Mariana Trench is far away from the mainland and located in the region of geolog- ical activities at the boundary of plates, the silt and clay may come from the earth inside through the geological movement, such as the eruption of submarine volcanoes and earthquakes [30]. The detritus of organisms is mainly formed by the sediment transported under ocean currents, such as diatoms and other plants. The low density, high water content, and high porosity of sediments can be attributed to its incomplete dense flocculation structure and the diatom fragments with many empty shells and pores.

The ultimate purpose of this research is to serve the development of deep-sea mining machines. Considering the interaction between the deep-sea mining machine and sediments, it is important to study the physical and mechanical properties of the sediments. Since it is difficult to core sediments from this area, the obtained experimental data will be used to predict the physical and mechanical properties of the Challenger Deep in the Mariana Trench. As a result, 


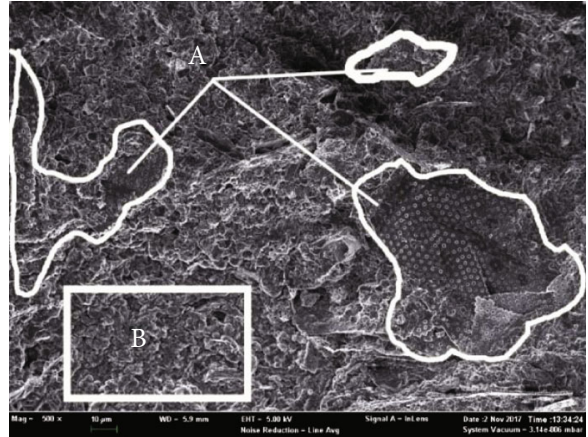

(a)

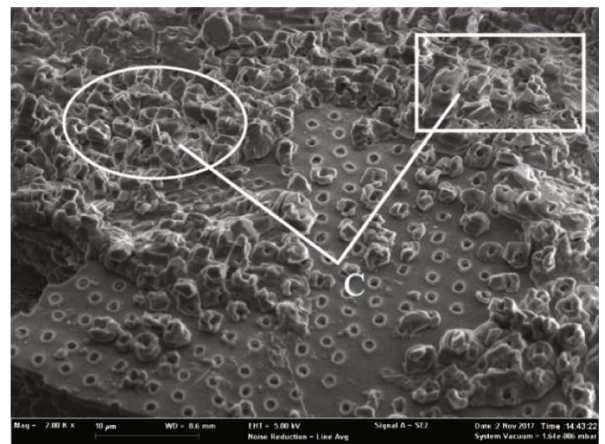

(b)

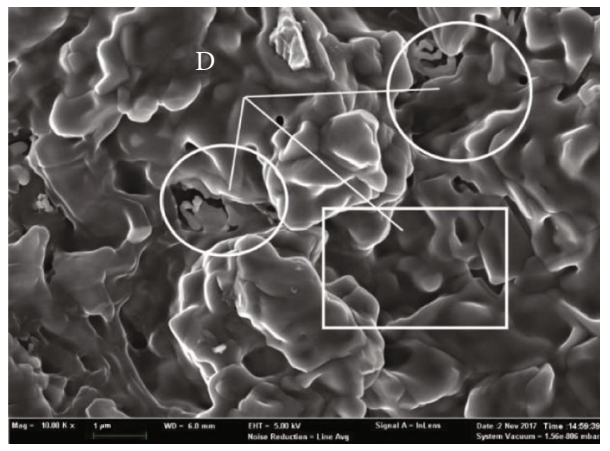

(c)

FIGURE 13: SEM image of undisturbed deep-sea sediments. (a) Sediments magnified 500 times. (b) Sediments magnified 2000 times. (c) Sediments magnified 10000 times.

it will contribute to the development of deep-sea mining machines. On the one hand, the characteristics of high porosity, low density, and high compressibility are determined by the soft flocculated microstructure of the sediments. Therefore, the bearing capacity and strength of the sediments in this area are very low, making it easy for the deep-sea mining machine to get trapped in them while driving on its surface. On the other hand, many interlaced fragments of porous diatoms induce internal low friction angle and cohesion force. As a consequence, it can be predicted that the sensitivity of the sediments in this area is very low and easy to slide under the disturbance of external load, which makes it easy for the deep-sea mining machine to slip on them.

\section{Conclusions}

By measuring the basic physical and mechanical properties of the deep oceanic sediments cored from the bottom of Challenger Deep in the Mariana Trench, the following conclusions can be drawn.

(1) The deep-sea sediments in this study are mainly flocculated structures composed of clay minerals, silt, and microbial detritus, which contain many porous diatom fragments with high water absorption

(2) A modified method for the measurement of physical and mechanical properties was proposed by taking the effect of salt in the pore water into account, the measured water content was increased by $11.68 \%$, and the measured specific gravity was decreased by $7.66 \%$

(3) In order to better develop the deep-sea mining vehicle, the simulation for this sediment should be introduced. The preparation principle of simulated deepsea soil is based on the consideration of particle size, water content, specific gravity, and shear strength, supplemented by liquid limit, plastic limit, and microstructure

(4) For the design of a deep-sea mining machine, the width and roughness of tracks should be appropriately increased to avoid sinking and skidding while traveling on the seabed

\section{Data Availability}

The data used to support the findings of the study are available from the corresponding author.

\section{Conflicts of Interest}

No potential conflict of interest was reported by the authors.

\section{Acknowledgments}

We are thankful to the crew of the R/V Tan Suo Yi Hao for their help during the expedition. We are also grateful to Dr. Yang Ning's team for their help during subsampling and analysis of the samples. This study was financially supported 
by the Research and Development of Key Technologies and Equipment for Deep-Sea Mineral Resources Exploration by the Chinese Academy of Sciences (SQ2016HYZY008).

\section{References}

[1] F. R. Gribble, R. J. Stern, S. H. Bloomer, D. Stüben, T. O'Hearn, and S. Newman, "MORB mantle and subduction components interact to generate basalts in the southern Mariana Trough back-arc basin," Geochimica et Cosmochimica Acta, vol. 60, no. 12, pp. 2153-2166, 1996.

[2] L. Xin, S. Z. Li, S. J. Zhao et al., "Structure of the Mariana subduction system," Earth Science Frontiers, vol. 24, pp. 329-340, 2017.

[3] M. Nakanishi and J. Hashimoto, "A precise bathymetric map of the world's deepest seafloor, Challenger Deep in the Mariana Trench," Marine Geophysical Research, vol. 32, no. 4, pp. 455-463, 2011.

[4] J. P. Barry and J. Hashimoto, "Revisiting the Challenger Deep using the ROVKaiko," Marine Technology Society Journal, vol. 43 , no. 5, pp. 77-78, 2009.

[5] M. Luo, T. J. Algeo, H. P. Tong et al., "More reducing bottomwater redox conditions during the last glacial maximum in the southern Challenger Deep (Mariana Trench, western Pacific) driven by enhanced productivity," Deep Sea Research Part II: Topical Studies in Oceanography, vol. 155, pp. 70-82, 2018.

[6] C. Cong, J. J. Long, and G. X. Li, "Experimental study on mechanical properties of seafloor sediments of deep South China Sea," The Ocean Engineering, vol. 33, pp. 108-114, 2015.

[7] R. D. Stoll, Y. F. Sun, and I. Bitte, "Seafloor properties from penetrometer tests," IEEE Journal of Oceanic Engineering, vol. 32, no. 1, pp. 57-63, 2007.

[8] J. Y. Wang, W. G. Cao, and Y. C. Zhai, "Experimental study of interaction between deep-sea sediments and tracks," Rock and Soil Mechanics, vol. 32, no. S2, pp. 274-278, 2011.

[9] H. van Haren, C. Berndt, and I. Klaucke, "Ocean mixing in deep-sea trenches: new insights from the Challenger Deep, Mariana Trench," Deep Sea Research Part I: Oceanographic Research Papers, vol. 129, pp. 1-9, 2017.

[10] J. V. Gardner, A. A. Armstrong, B. R. Calder, and J. Beaudoin, "So, how deep is the Mariana Trench?," Marine Geodesy, vol. 37, no. 1, pp. 1-3, 2014.

[11] L. J. Gao, J. Zhang, and S. G. Wu, "Analysis of lithospheric rheological structure and dynamics of the Challenger Deep in Mariana Trench," Journal of University of Chinese Academy of Sciences, vol. 34, pp. 380-388, 2017.

[12] X. Y. Cheng, J. Y. Wang, J. Y. Li, G. Y. Yan, and L. S. He, "Comparative analysis of the gut microbial communities between two dominant amphipods from the Challenger Deep, Mariana Trench," Deep Sea Research Part I: Oceanographic Research Papers, vol. 151, article 103081, 2019.

[13] J. Y. Li, C. Zeng, G. Y. Yan, and L. S. He, "Characterization of the mitochondrial genome of an ancient amphipod_Halice_ sp. MT-2017 (Pardaliscidae) from 10,908 $\mathrm{m}$ in the Mariana Trench," Scientific Reports, vol. 9, no. 1, article 2610, 2019.

[14] J. M. Liu, Y. F. Zheng, H. Y. Lin et al., "Proliferation of hydrocarbon-degrading microbes at the bottom of the Mariana Trench,” Microbiome, vol. 7, no. 1, p. 47, 2019.

[15] S. Q. Liu and X. T. Peng, "Organic matter diagenesis in hadal setting: insights from the pore-water geochemistry of the
Mariana Trench sediments," Deep Sea Research Part I: Oceanographic Research Papers, vol. 147, pp. 22-31, 2019.

[16] H. F. Wang, P. X. Lai, X. G. Deng et al., "Study on mineralogy, geochemistry and original environment of initial polymetallic oxides from the Challenger Deep, Mariana Trench," Journal of Marine Sciences, vol. 37, 29 pages, 2019.

[17] M. Luo, J. Gieskes, L. Y. Chen, X. H. Shi, and D. F. Chen, "Provenances, distribution, and accumulation of organic matter in the southern Mariana Trench rim and slope: implication for carbon cycle and burial in hadal trenches," Marine Geology, vol. 386, pp. 98-106, 2017.

[18] GB/T50123-1999, Standard for Soil Test Method, Standard, 1999.

[19] S. R. Wang, N. Yang, and G. M. Wang, "Strength characteristics of deep-sea deposits in China's mining region in the Pacific Ocean's C-C zone," Mining and Metallurgical Engineering, vol. 20, pp. 21-24, 2000.

[20] Y. J. Yu, L. C. Dan, H. F. Wang, X. Duan, and K. J. Zhu, "Preliminary study on physico-mechanical properties of deep-sea sediments from the Western Pacific," Mining and Metallurgical Engineering, vol. 36, pp. 1-4, 2016.

[21] E. L. Hamilton, "Prediction of in-situ acoustic and elastic properties of marine sediments," Geophysics, vol. 36, no. 2, pp. 266-284, 1971.

[22] T. Nunoura, M. Nishizawa, M. Hirai et al., "Microbial diversity in sediments from the bottom of the Challenger Deep, the Mariana Trench," Microbes and Environments, vol. 33, no. 2, pp. 186-194, 2018.

[23] W. E. Hottman, "Deep-sea sediments, physical and mechanical properties," Earth-Science Reviews, vol. 12, no. 4, pp. 450450, 1976.

[24] W. G. Cao, J. Y. Wang, Y. C. Zhai, and H. Zhao, "Statistical damage method for simulation of shear deformation process of deep-sea sediments," Chinese Journal of Geotechnical Engineering, vol. 33, no. 6, pp. 40-44, 2011.

[25] A. W. Mantyla and J. L. Reid, "Measurements of water characteristics at depths greater than $10 \mathrm{~km}$ in the Marianas Trench," Deep-Sea Research, vol. 25, no. 2, pp. 169-173, 1978.

[26] L. Q. Song, "Geotechnical properties of oceanic polymetallic nodule sediments," Acta Oceanologica Sinica, vol. 21, pp. 4754, 1999.

[27] W. B. Ma, Q. H. Rao, H. Y. Wu, S. C. Guo, and P. Li, "Macroscopic properties and microstructure analyses of deep-sea sediment," Rock and Soil Mechanics, vol. 35, pp. 1641-1646, 2014.

[28] J. Zhou, Y. L. Deng, Y. Cao, and J. J. Yan, "Experimental study of microstructure of Hangzhou saturated soft soil during consolidation process," Journal of Central South University (Science and Technology), vol. 45, pp. 1998-2005, 2014.

[29] T. R. Mao and L. Xia, "Experimental research on microstructure of expansive soil in north of Hubei Province," Journal of Huazhong University of Science and Technology, vol. 27, pp. 48-52, 2010.

[30] W. X. Wu, F. Q. Gong, and W. M. Yang, "Experimental simulation study of spalling in deep rectangular tunnel with plastic fine grain marble," Tunnelling and Underground Space Technology, vol. 98, article 103319, 2020. 